\title{
Peristiwa Pemberantasan PGRS-Paraku di Kalimantan Barat Tahun 1967
}

\author{
YULITA DEWI PURMINTASARI \\ Jurusan Pendidikan Sejarah, STKIP PGRI Pontianak \\ yulita.dewi46@yahoo.com
}

\begin{abstract}
Abstrak
Penelitian ini bertujuan:mendapatkan informasi yang objektif mengenaiperistiwa pemberantasan PGRS/Paraku di Kalimantan Barat, analisis teori hegemoni Gramsci terhadap peristiwa pemberantasan PGRS/Paraku, pembelajaran sejarah lokal melalui materi peristiwa pemberantasan PGRS/Paraku. Penelitian ini menggunakan metode deskriptif dengan bentuk studi kasus terpancang. Sumber data adalah narasumber dari dosen dan mahasiswa. Teknik pengumpulan data berupa observasi langsung dengan panduan observasi dan komunikasi langsung dengan panduan wawancara.Hasil penelitian menunjukkan: PGRS/ Paraku dibentuk ketika terjadi konfrontasi Indonesia-Malaysia. Namun ketika Orde Baru, PGRS/Paraku yang menjadi garda terdepan dalam konfrontasi diperangi. Dalam penumpasan PGRS/Paraku sebagai bentuk kecil hegemoni di Kalimantan Barat, tindakan kekerasan yang bersifat memaksa dilakukan oleh militer, dalam hal ini angkatan darat. Masyarakat Dayak di perbatasan menghimpun kekuatan bersama ABRI melawan komunis yang telah memecah belah mereka dan menumpas PGRS/Paraku.Melalui kajian hegemoni Gramsci, kajian ini dapat menjadi materi pembelajaran sejarah lokal yang perlu dikembangkan untuk menambah pengetahuan serta meningkatkan nasionalisme dan patriotisme generasi mendatang.
\end{abstract}

Kata Kunci : PGRS/Paraku, Hegemoni Gramsci

\begin{abstract}
This research aims to obtain the objective information about the eradication of PGRS / Paraku in West Kalimantan, the analysis of Gramsci's theory of hegemony towards the eradication of PGRS / Paraku, local history learning through events of PGRS / Paraku eradication. This research employs descriptive method with fixed form of case studies. The data sources were lecturers and students. Data collection techniques include direct observation with the use of observation guidelines and direct communication with the use of interview guidelines. The research findings show: PGRS / Paraku was established when the Indonesia-Malaysia confrontation occured but PGRS / Paraku which became the forefront of confrontation was fought during the New Order. In destroying PGRS / Paraku as a small form of hegemony in West Kalimantan, the acts of violence committed by the military, in this case the army. Dayak communities in the border collaborated with the armed forces gather strength against the communists who have divided them and quell PGRS / Paraku. Through hegemony of Gramsci studies, this research can be a local history learning materials that need to be developed to increase knowledge and improve the nationalism and patriotism of the next generation.
\end{abstract}

Keywords: PGRS / Paraku, Gramsci Hegemony 


\section{PENDAHULUAN}

Kalimantan Barat sebagai bagian dari Indonesia memiliki andil yang besar dalam percaturan politik di Indonesia.Kondisi ini akanterlihat pada saat adanya rencana pembentukan Negara Federasi Malaysia. Suatu rencana untuk menggabungkan negara-negara bekas jajahan Inggris dalam satu payung. Presiden Soekarno berpendapat bahwa Malaysia hanya sebuah boneka Inggris, dan konsolidasi Malaysia hanya akan menambah kontrol Inggris di kawasan ini Asia Tenggara, sehingga mengancam kedaulatan Indonesia.

Soekarno melancarakan seruan Ganyang Malaysia untuk menyelamatkan rakyat Malaysia dari bahaya neokolim Inggris.Penentangan ini ditanggapai Soekarno dengan memberikan dukungan pada Pasukan Gerilya Rakyat Serawak (PGRS) dan Pasukan Rakyat Kalimantan Utara (Paraku). Orang-orang yang tergabung dalam PGRS-Paraku sebagian besar adalah etnis Tionghoa dan prokomunis. Namun setelah terjadinya tragedi G $30 \mathrm{~S}$ tahun 1965, kondisi politik di Indonesia berubah.Peristiwa tersebut melemahkan dominasi PKI dalam pemerintahan.

Soeharto segera menyelesaikan masalah konfrontasi Indonesia-Malaysia dengan ditandatanganinya Jakarta Accord.Pemeritahan Soeharto segera menumpas PGRS-Paraku, hal ini sesuai dengan Tap MPRS No.XXV/ MPRS/1966 yang melarang ajaran marxisme-leninisme di Indonesia.Operasi-operasi penumpasan yang dilakukan Tentara Indonesia berhasil melumpuhkan PGRS-Paraku.

Penetrasi ideologi sangat kental sekali dalam Pemberantasan PGRS-Paraku yang menunjukkan adanya hegemoni dan dominasi suatu kekuasaan penguasa. Sangat menarik melihat seperti apa hegemoni kekuasaan yang terjadi dalam pemerantasan PGRS-Paraku melalui kacamata teori hegemoni Gramsci. Kajian ini akan menambahkan khasanah kajian sejarah lokal di Kalimantan Barat. Maka dari itu peneliti tertarik untuk melakukan penelitian yang mengkaji peristiwa pemberantasan PGRS-Paraku yang dikaji dengan teori hegemoni Gramsci yang menjadi salah satu pembahasan dalam materi sejarah lokal.
METODE

\section{Bentuk Penelitian}

Strategi dalam penelitian ini adalah penelitian studi kasus terpancang (embedded research), yaitu penelitian kualitatif yang sudah menentukan fokus penelitiannya (Yin lewat Sutopo, 2006: 39), sehingga dalam pengambilan data terlebih dahulu sudah ditetapkan obyek penelitiannya dalam rangka mendapatkan informasi atau fakta sesuai dengan harapan peneliti yaitu berupa penelusuran fakta sejarah mengenai hegemoni yang ada dalam peristiwa pemberantasan PGRS-Paraku tahun 1967 di Kalimantan Barat.

\section{Sumber Data}

Data atau informasi yang paling penting untuk dikumpulkan dan dikaji dalam penelitian ini sebagian besar berupa data kualitatif.

1. Informan atau narasumber dalam penelitian ini adalah Susi Susanti,S.Pdi.M.Pd selaku dosen mata kuliah sejarah lokal, para mahasiswa semester IV Program Studi Pendidikan Sejarah STKIP PGRI Pontianak.

2. Tempat dan peristiwa/aktivitas terdiri dari kegiatan pembelajaran yang dilakukan oleh dosen dalam kelas.

3. Arsip dan dokumen

Arsip dan Dokumen merupakan bahan tertulis yang berkaitan dengan suatu peristiwa atau aktivitas tertentu.Oleh karena itu dokumen dan arsip bukan hanya menjadi sumber data yang penting bagi penelitian kesejarahan, tetapi juga dalam penelitian kualitatif pada umumnya (Sutopo, 2006:61-62).

\section{Instrumen Penelitian}

Instrumen yang digunakan dalam penelitian ini adalah panduan observasi, panduan wawancara dan lembar telaah dokumen.

\section{Validitas Data}

Secara umum dalam penelitian kualitatif teknik pengembangan validitas data yang digunakan adalah teknik trianggulasi (Patton, 1980: 161).

1. Trianggulasi data (Data Triangulation) 
Trianggulasi sumber adalah teknik trianggulasi yang dilakukan dengan mengumpulkan data sejenis dari beberapa sumber data yang berbeda. Dalam penelitian ini pemberantasan PGRS-Paraku di Kalimantan Barat tahun 1967 (kajian teori hegemoni Gramsci untuk pembelajaran sejarah lokal), dan alasan diterapkannya pemberantasan PGRS-Paraku di Kalimantan Barat tahun 1967 (kajian teori hegemoni Gramsci untuk pembelajaran sejarah lokal) dan hasil setelah diterapkannya pendidikan ini dapat digali dari sumber data yang berbeda berupa informan/narasumber, peristiwa/ aktivitas dan arsip/dokumen.

2. Triangulasi teori (Theory triangulation)

Menggunakan beragam perspektif untuk menginterpretasikan sekelompok data tunggal.Trianggulasi jenis ini dilakukan oleh peneliti dengan menggunakan perspektif lebih dari satu teori dalam membahas permasalahan yang dikaji.Maka dari itu dalam melakukan trianggulasi teori, peneliti wajib memahami teori-teori yang digunakan dan keterkaitannya dengan permasalahan yang diteliti sehingga mampu menghasilkan simpulan yang lebih mantap, bisa dipertanggungjawabkan dan benar-benar memiliki makna yang mendalam serta bersifat multiperspektif (Sutopo, 2006: 99).

3. Trianggulasi metodologis (methodological trianggulation)

Trianggulasi metode adalah teknik trianggulasi yang dilakukan dengan mengumpulkan data sejenis dengan menggunakan metode yang berbeda.Data sejenis yang dikumpulkan dengan metode yang berbeda dibandingkan dan ditarik simpulan data yang lebih kuat validitasnya (Sutopo, 2006: 95).

\section{Teknik Analisis Data}

Teknik analisis dalam penelitian ini bersifat induktif yaitu teknik analisis yang tidak dimaksudkan untuk membuktikan suatu prediksi atau hipotesis penelitian, tetapi simpulan dan teori yang dihasilkan berbentuk dari data yang dikumpulkan. Sifat analisis induktif menekankan pentingnya apayang sebenar terjadi di lapangan yang bersifat khusus berdasarkan karakteristik konteksnya. Dalam penelitian ini analisis induktif yang digunakan adalah teknik analisis interaktif, yaitu setiap data yang diperoleh dari lapangan selalu diinteraksikan atau dibandingkan dengan unit data yang lain (Sutopo, 2006: 107). Dalam proses analisis interaktif terdapat 4 komponen yang harus dipahami oleh peneliti yaitu: (1) pengumpulan data, (2) reduksi data,(3) sajian data (4) penarikan simpulan/verifikasi. Empat komponen tersebut harus berkaitan, selalu terlibat dalam proses analisis, dan memberi arahan dalam simpulan serta selalu dibandingkan untuk pemantapan pemahaman, sebagaimana dijelaskan berikut ini.

1. Pengumpulan data

Dalam analisis data langkah awal yang perlu dilakukan, peneliti harus mengumpulkan data yang diperoleh sebelum melakukan reduksi.Data yang dikumpulkan bisa data dari lapangan (fieldnotes) dan teori-teori yang berkaitan dengan tema yang diambil peneliti.

\section{Reduksi data (data reduction)}

Reduksi data merupakan proses pemilihan, pemfokusan, penyederhanaan dan abtraksi data kasar yang ada dalam fieldnotes (catatan lapangan).

3. Sajian data (data display)

Sajian data merupakan rakitan organisasi informasi, deskripsi dalam bentuk narasi lengkap sehingga simpulan penelitian dapat dilakukan.

4. Penarikan simpulan/ verifikasi (conclusion drawing/verifying)

Sejak tahap awal pengumpulan data, peneliti harus sudah mulai memahami makna dari berbagai hal yang ditemukan, pernyataan-pernyataan, konfigurasi-konfigurasi yang mungkin, alur sebab akibat dari berbagai porsi.Selanjutnya setelah verifikasi dilakukan penarikan simpulan.

\section{HASIL DAN PEMBAHASAN}

\section{Sajian Data}

1. PGRS/Paraku di Kalimantan Barat 
Terbentuknya PGRS/Paraku tidak dapat dilepaskan dari konflik Indonesia Malaysia. Konflik ini tidak memakan waktu yang terlalu lama, akan tetapi mempunyai pengaruh yang cukup besar bagi perkembangan Indonesia. Sejak awal, pemerintah Indonesia menolak pembentukan Federasi Malaysia yang didukung penuh oleh Inggris.Wilayah Kalimantan Utara juga merupakan daerah koloni Inggris. Seperti halnya Semenanjung Malaya, Kalimanta Utara juga dimasukan dalam teritori federasi Malaysia dan tanpa meminta persetujuan dari penduduk Kalimantan Utara. Penolakan penduduk, khususnya warga keturunan Cina (Tionghoa), didasari pada kecemasan akan adanya dominasi warga Melayu semenanjung Malaya terhadap rakyat Kalimantan Utara.

Gerakan PGRS /Paraku dikatakan merupakan suatu gerakan anarkis, sehingga mengganggu stabilitas sosial politik di Kalimantan Barat. Menghadapi kondisi yang demikian, maka diperlukan sikap yang jelas dan tegas dari pemerintah Indonesia untuk menindaklanjuti gerakan PGRS/Paraku tersebut yang dianggap gerakan terlarang dan dipandang sebagai ancaman terhadap Indonesia. Sikiap pmerintah Indonnesia lebih menyangkut pada hubungan internasional, khususnya masalah perbatasan karena daerah operasi PGRS/Paraku bukan hanya di daerah kekuasaan Indonesia. Tetapi juga di Serawak (bagian Federasi Malaysia), sehingga dalam hal ini pemerintah Indonesia harus memiliki suatu bentuk kerjasama antara Indonesia dengan Malaysia untuk menerapkan prinsip keamanan besama.

2. Analisis teori hegemoni Gramsci terhadap peristiwa pemberantasan PGRS/Paraku

Seperti yang telah dibahas sebelumnya, bahwasannya kemunculan PGRS Paraku tahun 1963 berkaitan dengan kepentingan politik Indonesia, yaitu untuk menangani konfrontasi Indonesia Malaysia, dimana Indonesia pada saat kepemimpinan Soekarno menolak untuk didirikannya Federasi Malaysia oleh Inggris. PGRS/Paraku menjadi sesuatu yang sangat menarik ketika pemerintahan Soeharto seakan-akan menjadi mu- suh yang paling berbahaya yang harus segera dimusnahkan.Hal ini bukan sesuatu yang aneh, karena anggota PGRS/Paraku menganut paham komunisme, sedangkan Soeharto sebagai tampuk kepemimpinan tertinggi di Indonesia saat itu antipati dengan komunis. Soeharto segera mengeluarkan Tritura untuk membersihkan negara dari segala unsur PKI.

Dapat kita lihat bahwa PGRS/Paraku terombang-ambing antara dua kekuatan ideologi yang besar dan sangat berpengaruh kala itu. Secara kasar, sosialisme dan komunisme pada masa pemerintahan Soekarno memiliki tempat tersendiri dan dapat dengan bebas menjalankan segala kegiatan mereka. Hal ini disebabkan Soekarno mengusung paham Nasakom dalam menjalankan pemerintahannya. Akan tetapi setelah tumbangnya Soekarno, kondisi politik di Indonesia mulai berubah haluan. Kebijakan Tritura yang dilakukan Soeharto terlihat adanya keinginan untuk menciptakan suatu hegemoni agar konsep kehidupan yang ditawarkan Soeharto dapat diterima oleh rakyat Indonesia.

Antonio Gramsci, seorang tokoh pembaharuan terhadap konsep Marxis menyatakan bahwa hegemoni atau dominasi merupakan suatu bentuk supremasi suatu kelompok atau beberapa kelompok atas yang lainnya, atas bentuk supremasi yang lain yang dinamakan "dominasi" yaitu kekuatan yang ditopang oleh kekuatan fisik. Sejalan dengan pemerintahan baru di bawah Soeharto memaksa rakyat menerima nilai-nilai dan ideologi yang terus diperjuangkan dan dipertahankan oleh pihak yang dominan, sehingga pihak yang didominasi tetap diam dan taat terhadap dominasi kepemimpinan penguasa.

3. Pembelajaran sejarah lokal melalui materi peristiwa pemberantasan PGRS-Paraku

Pembelajaran sejarah lokal dilaksanakan di kelas A pagi semester IV program studi pendidikan sejarah. Pembelajaran dilaksanakan pada hari Rabu, tanggal 14 Mei 2014. Dalam proses pembelajaran sejarah lokal, kelas dibagi dalam beberapa kelompok dimana masing-masing kelompok mendapatkan materi sejarah lokal sesuai dengan kurikulum. Salah satunya adalah materi PGRS/Paraku. 
Materi PGRS/Paraku disampaikan melalui sebuah diskusi. Mahasiswa antusias ketika mengikuti proses pembelajaran, baik ketika sesi tanya jawab maupun mendengarkan penjelasan dari dosen, hal ini dikarenakan PGRS/Paraku merupakan salah satu peristiwa yang fenomenal. PGRS/Paraku tersebut merupakan peristiwa sejarah lokal yang dapat menambah pengetahuan dan wawasan baru bagi mahasiswa, menumbuhkan kesadaran mahasiswa untuk menggali sejarah yang ada di daerah mereka serta meningkatkan rasa nasionalisme dan jiwa patriotisme.

Proses diskusi didampingi oleh Susi Susanti,S.Pdi.,M.Pd. selaku dosen pengampu mata kuliah sejarah lokal. Dosen memberikan kebebasan pada mahasiswa untuk berdiskusi. Setelah diskusi ditutup, dosen menjelaskan kembali materi PGRS/Paraku. Memberikan analisis tambahan terhadap peristiwa PGRS/Paraku.Pada akhir pembelajaran, bersama-sama dengan mahasiswa menyimpulkan materi pembelajaran.

\section{Pembahasan}

1. Pemberantasan PGRS/Paraku di Kalimantan Barat

Dalam mengkaji kaitan hegemoni kekuasaan Soeharto dalam pemberantasan PGRS/ Paraku, tidak dapat dilepaskan dari politik Soekarno dan Soeharto. Maka dari itu disini akan dibahas sedikit tentang politik Soekarno dan Soeharto serta kontribusinya dalam pembentukan dan pemberantasan PGRS/ Paraku di Kalimantan Barat.

Pada masa Demokrsi Terpimpin ini PKI mendapatkan kedudukan penting.Kaderkader PKI banyak yang duduk dalam DPRGR, DPA dan Pengurus Besar Front Nasional serta daerah. Berangkat dari dukungan Soekarno terhadap PKI dan menjadikan PKI sebagai garis depan dalam pemerintahannya, sudah jelas terlihat ke arah mana politik yang diusung oleh Soekarno. Dari sini akan membawa kita pada bagaimana kontribusi komunis di Kalimantan Barat dalam pemerintahan dan proyek politik Soekarno.

Kalimantan Barat merupakan salah satu wilayah Indonesia yang berada dalam satu daratan dengan Malaysia dan Brunei.Ing- gris berusaha untuk menggabungkan koloni-koloninya di Asia Tenggara dalam satu kesatuan.Malaysia yang berada di bawah negara persemakmuran, segera mendekat ke Inggris.Rencana tersebut ditentang oleh Pemerintahan Indonesia. Presiden Soekarno berpendapat bahwa Malaysia hanya sebuah boneka Inggris, dan konsolidasi Malaysia hanya akan menambah kontrol Inggris di kawasan ini, sehingga mengancam kemerdekaan Indonesia.

Sebagai usaha menentang pembentukan Federasi Malaysia, Soekarno menyerukan Ganyang Malaysia dan mengumpulkan para relawan. Relawan ini banyak terdiri dari orang-orang Cina.Perkembangan selanjutnya kelompok ini membentuk Pasukan Rakyat Kalimantan Utara (Paraku) ataupun Pasukan Gerilya Rakyat Serawak (PGRS) yang mayoritas etnis Tionghoa.Kedua pasukan tersebut dibawah komanado Brigadir Jenderal Supardjo, yang pada saat itu menjabat sebagai Panglima Komando Tempur IV Mandau dengan pusat kedudukan di Bengkayang, Kalimantan Barat.Untuk itu, Resimen Khusus Angkatan Darat (RPKAD) ditugaskan untuk melatih sukarelawan tersebut.

Menjelang akhir 1965, Jendral Soeharto memegang kekuasaan di Indonesia setelah berlangsungnya G30S/PKI.Oleh karena konflik domestik ini, keinginan Indonesia untuk meneruskan perang dengan Malaysia menjadi berkurang dan peperangan pun mereda. Tetapi setelah Soeharto dapat duduk dalam tampuk kepemimpinan Indonesia, berlangsung pembantaian orang-orang yang dianggap komunis.Hal ini dikarenakan bedanya pandangan ideologi Soeharto dengan komunis.Usaha untuk menghabisi komunis di Kalimantan Barat baru terjadi setelah adanya rekonsiliasi dengan Malaysia.

Rekonsialiasi dan Perubahan politik menyebabkan Indonesia tidak lagi sejalan dengan politik PGRS-Paraku.Justru menciptakan situasi yang kacau, menjadikan PGRS/Paraku sebagai pendatang liar di daerah perbatasan Serawak dan Kalimantan Barat.Mereka hidup bergerilya, terjepit di antara tentara Indonesia dan Malaysia.Operasi untuk menumpas gerilyawan PGRS/Paraku berjalan sangat su- 
lit, karena PGRS/Paraku selalu menghindari pertempuran terbuka.Dengan jumlah personil dan persenjataan yang terbatas mereka hanya beroperasi di hutan-hutan. Orangorang yang simpati kepada PGRS/Paraku masuk ke hutan Kalimantan Barat untuk bergabung dengan mereka di sana. Bulan Juli 1967 PGRS-Paraku menyerang pangkalan udara militer Indonesia di Sanggauledo.Beberapa perwira dan staffnya dibunuh.Mereka juga merebut senjata dan amunisi tentara.

Penumpasan PGRS/Paraku oleh militer mengalami kegagalan.Salah satu penyebab kegagalan tersebut adalah terbatasnya pihak militer setempat baik dalam hal persenjataan maupun dari segi jumlah personil militer yang ada. Mengingat keterbatasan militer setempat, pemerintah mendatangkan pasukan dari Jawa untuk membantu proses penumpasan PGRS-Paraku. Pasukan yang didatangkan yaitu pasukan divisi Siliwangi. Pasukan ini tidak menguasai medan operasi, oleh karena itu mereka merekrut beberapa warga sipil sebagai pasukan terdepan. Mereka yang direkrut adalah yang dinilai menguasai medan operasi sebagai penunjuk jalan. Terbentuklah pasukan-pasukan tambahan seperti pasukan Kancil dan pasukan Kalajengking. Mereka dipersenjatai lengkap dengan seragam militernya.

Militer juga meminta dukungan mantan Gubernur Kalimantan Barat Oevang Oeray supaya orang Dayak dapat membantu tentara untuk menumpas para pemberontak.Masyarakat Dayak dihimbau untuk ikut berpartisipasi bersama tentara untuk menumpas PGRS/Paraku.Militer melakukan propaganda di kalangan tokoh Dayak dengan menyebarkan beberapa isu bahwa orang-orang komunis tidak menyukai sistem Dayak.

2. Analisis teori hegemoni Gramsci terhadap peristiwa pemberantasan PGRS/Paraku

Dalam pandangan postmodernisme, teori hegemoni menjadi sudut pandang kajian peristiwa pemberanguasan PKI dalam artian PGRS/Paraku.Secara literal, hegemoni berarti kepemimpinan.Secara hemat hegemoni merupakan suatu dominasi suatu pihak dalam seluruh aspek.Hegemoni bukan- lah hubungan dominasi dan menggunakan kekuasaan, hegemoni adalah hubungan persetujuan dan menggunakan kepemimpinan politik-ideologis.

Soeharto memaksakan agar rakyat menerima nilai-nilai dan ideologi yang terus diperjuangkan dan dipertahankan oleh pihak yang dominan, sehinggga pihak yang didominasi tetap diam dan taat terhadap dominan kepemimpinan penguasa.Analisis utama hegemoni dalam peristiwa mangkok merah yang didalamnya berusaha untuk memberantas PGRS/Paraku adalah bagaimana Soeharto memberikan kuasa politik ideologisnya dalam usaha untuk memberantas PGRS/ Paraku.

Melalui konsep hegemoni, Gramsci beragumentasi bahwa kekuasaan agar dapat abadi dan langgeng membutuhkan paling tidak dua perangkat kerja. Pertama, adalah perangkat kerja yang mampu melakukan tindak kekerasan yang bersifat memaksa atau dengan kata lain kekuasaan membutuhkan perangkat kerja yang bernuansa law enforcemant. Perangkat kerja yang pertama ini biasanya dilakukan oleh pranata negara (state) melalui lembaga-lembaga seperti hukum, militer, polisi dan bahkan penjara. Dalam peristiwa ini lembaga yang paling menonjol adalah militer, tepatnya AD yang sangat memainkan peranan yang dominan sekali.AD menjadi garda terdepan dalam pemberantasan anggota PGRS/Paraku inidan Soeharto memberikan kontrol yang sangat ketat.Soeharto berusaha keras untuk melaksanakan tritura, yang digembar-gemborkan dalam upaya kudeta secara halus kepemimpinan Soekarno.

Perangkat kerja yang kedua, adalah perangkat kerja yang mampu membujuk masyarakat beserta pranata-pranata untuk taat pada mereka yang berkuasa melalui kehidupan beragama, pendidikan, kesenian dan bahkan juga keluarga (Heryanto, 1997 lewat Saptono, 2014: 1).Dalam memantapkan hegemoni kekuasaannya, Soeharto bersama dengan AD memanfaatkan kelompok etnis Dayak.Mereka menyebarkan propaganda kepada orang-orang Dayak betapa bahayanya ajaran komunisme, dan komunisme tidak menyukai sistem Dayak, sehingga komu- 
nisme harus dibumihanguskan. Dalam hal ini orang-orang yang tergabung dalam PGRS/ Paraku adalah etnis Tionghoa yang pro-komunis. Namun demikian, semua etnis Tionghoa bagi orang-orang Dayak adalah komunis, sehingga memunculkan salah persepsi yang mengakibatkan peristiwa Mangkok Merah tidak sekedar kepentingan politik dominasi kekuasaan, namun jauh dari itu berubah menjadi konflik etnis yang cukup berbahaya. Kedua level ini pada satu sisi berkaitan dengan fungsi hegemoni dimana kelompok dominan menangani keseluruhan masyarakat dan disisi lain berkaitan dengan dominasi langsung atau perintah yang dilaksanakan diseluruh negara dan pemerintahan yuridis (Gramsci, 1971 lewat Saptono, 2014: 1).

Kedua hal tersebut sangat penting untuk membentuk sebuah negara integral. Komninasi kompleks antara "kedidaktoran dan hegemoni" atau seluruh kompleks aktivitas praktis dan teoritis dimana kelas berkuasan tidak hanya menjustifikasi dan menjaga dominannya, tetapi juga berupaya memenangkan persetujuan aktif dari mereka yang dikuasai (Nezar; 2009: 151).Dalam membentuk Negara integral, Soeharto cenderung menggunakan paksaan, terutama kepada masyarakat sipil agar mau dan bisa menerima ideologi yang dibawanya. Apabila ideologi sudah berhasil ditanamkan, maka aspek yang lain, misalnya ekonomi dan politik akan sangat mudah untuk dikontrol, sehingga akan sangat mudah untuk mewujudkan Negara integral yang terdiri dari masyarakat sipil dan masyarakat politik. Walaupun dalam keberlangsungannya akan sangat terlihat adanya kediktatoran yang berujung pada hegemoni.

3. Pembelajaran sejarah lokal melalui materi peristiwa pemberantasan PGRS-Paraku

Kajian peristiwa pemberantasan PGRS/ Paraku melalui kajian hegemoni Gramsci dapat menjadi suatu materi pembelajaran sejarah lokal. Mahsiswa dapat menggali sejarah lokal yang ada dan dapat menambah pengetahuan baik bagi mahasiswa maupun dosen serta dapat meningkatkan rasa nasionalisme pada mahasiswa generasi yang akan datang. Sejarah lokal mengangkat peristiwa-peristi- wa lokal atau kedaerahan. Sejarah lokal inilah yang nantinya akanmembentuk sejarah nasional.

Melalui pembelajaran sejarah lokal dapat menumbuhkan kesadaran terhadap daerah masing-masing. Hal ini disebabkan sejak sekolah dasar hingga perguruan tinggi, pembelajaran sejarah hanya diutamakan mempelajari sejarah yang berskala nasional. Sehingga siswa tidak dapat mengetahui sejarah daerah mereka.Dengan duduk di bangku kuliah dan memepelajari sejarah lokal memberikan keuntungan sendiri untuk mahasiswa, selain mereka dapat mengetahu sejarah daerah mereka masing-masing, mereka dapat pula mengkaitkan peristiwa nasional serupa yang sezaman dengan peristiwa yang ada di daerah mereka.

\section{SIMPULAN}

Berdasarkanpembahasan penelitian yang telah diuraikan ditas maka dapat ditarik kesimpulan bahwa PGRS/Paraku dibentuk ketika Orde Lama dibawah kepemimpinan Soekarno. Mereka dibentuk ketika terjadi konfrontasi antara Indonesia Malaysia, dimana Soekarno tidak setuju terhadap pembentukan Federasi Malaysia. Sikap Soekarno ini didukung oleh rakyat Kalimantan Utara. Namun ketika Orde Baru, kondisi menjadi berubah. PGRS/Paraku yang dulunya menjadi garda terdepan dalam konfrontasi akhirnya diperangi dan dibumihanguskan. Bahkan konflik ini menjadi konflik yang lebih jauh menjadi sebuh konflik rasialis.

Teori hegemoni Gramsci membantu dalam menganalisis peristiwa pemberantasan PGRS/Paraku. Hegemoni merupakan alat untuk melanggengkan kekuasaan. Dalam penumpasan PGRS/Paraku sebagai bentuk kecil hegemoni di Kalimantan Barat, tindakan kekerasan yang bersifat memaksa dilakukan oleh militer, dalam hal ini adalah angkatan darat. AD menjadi garda terdepan dalam pemberantasan anggota PGRS/Paraku. Soeharto memberi kontrol yang sangat ketat untuk dapat mengendalikan situasi di lapangan. Soeharto berusaha keras untuk melaksanakan Tritura, yang digembar-gemborkan 
dalam upaya kudeta secara halus di bawah kepemimpinan Soeharto. Selain dengan kekuatan militer, bantuan dari rakyat Dayak merupakan hal unik. Masyarakat Dayak di daerah perbatasan menghimpun kekuatan bersama-sama ABRI melawan komunis yang telah memcah belah mereka dan menumpas PGRS/Paraku.

Kajian peristiwa pemberantasan PGRS/ Paraku melalui kajian hegemoni Gramsci dapat menjadi suatu materi pembelajaran sejarah lokal. Mahsiswa dapat menggali sejarah lokal yang ada dan dapat menambah pengetahuan baik bagi mahasiswa maupun dosen serta dapat meningkatkan rasa nasionalisme pada mahasiswa generasi yang akan datang. Sejarah lokal mengangkat peristiwa-peristiwa lokal atau kedaerahan. Sejarah lokal ini lah yang nantinya akan membentuk sejarah nasional.

\section{UCAPAN TERIMA KASIH}

Penulis mengucapkan terima kasih kepada dewan redaksi Jurnal Socia atas kesempatan yang diberikan sehingga paper ini dapat diterbitkan pada Jurnal Socia edisi Mei 2015.

\section{DAFTAR PUSTAKA}

Nezar, P. dan Andi, A. 2009. Antonio Gramsci Negara dan Hegemoni. Yogyakarta: Pustaka Pelajar.

Patton, M.Q. 1980. Qualitative Evaluation Methods. Berverly Hills, CA: Sage Publication.

Saptono. 2014. Teori Hegemoni Sebuah Teori Kebudayaan Kontemporer. http://repo. isi-dps.ac.id/226/1/Teori_Hegemoni_Sebuah_Teori_Kebudayaan_Kontemporer. pdf diunduh 14 Juli 2015

Sutopo, H.B. 2006.Metodologi Penelitian Kualitatif. Surakarta: UNS Press 